\title{
Radial profile of sap flow velocity in mature Xinjiang poplar (Populus alba L. var. pyramidalis) in Northwest China
}

\author{
HongZhong DANG ${ }^{1 *}$, TianShan $Z \mathrm{HA}^{2}$, JinSong ZHANG ${ }^{3}$, Wei $\mathrm{LI}^{1}$, ShiZeng $\mathrm{LIU}^{4}$ \\ ${ }^{1}$ Institute of Desertification Studies, Chinese Academy of Forestry, Beijing 100091, China; \\ ${ }^{2}$ School of Soil and Water Conservation, Beijing Forestry University, Beijing 100083, China; \\ ${ }^{3}$ Research Institute of Forestry, Chinese Academy of Forestry, Beijing 100091, China; \\ ${ }^{4}$ Gansu Desert Control Research Institute, Lanzhou 730070, China
}

\begin{abstract}
Estimation of the transpiration rate for a tree is generally based on sap flow measurements within the hydro-active stem xylem. In this study, radial variation of sap flow velocity $\left(J_{s}\right)$ was investigated at five depths of the xylem (1, 2, 3, 5 and $8 \mathrm{~cm}$ under the cambium) in three mature Xinjiang poplar (Populus alba L. var. pyramidalis) trees grown at the Gansu Minqin National Studies Station for Desert Steppe Ecosystem from May to October 2011. Thermal dissipation probes of various lengths manufactured according to the Granier's design were installed into each tree for simultaneous observation of the radial patterns of $J_{s}$ through the xylem. The radial patterns were found to fit the four-parameter GaussAmp equation. The peak $J_{s}$ was about $27.02 \pm 0.95 \mathrm{~kg} /\left(\mathrm{dm}^{2} \cdot \mathrm{d}\right)$ at approximately 3 to 5 $\mathrm{cm}$ deep from the cambium of the three trees, and the lowest $J_{s}$ appeared at $1 \mathrm{~cm}$ deep in most of the time. Approximately $50 \%$ of the total sap flow in Xinjiang poplar occurred within one-third of the xylem from its outer radius, whereas $90 \%$ of the total sap flow occurred within two-fifth of the xylem. In addition, the innermost point of the xylem (at 8-cm depth), which appeared as the penultimate sap flow in most cases during the study period, was hydro-active with $J_{s, 8}$ of $7.55 \pm 3.83 \mathrm{~kg} /\left(\mathrm{dm}^{2} \cdot \mathrm{d}\right)$. The radial pattern of $J_{s}$ was found to be steeper in midday than in other time of the day, and steeper diurnal fluctuations were recorded in June, July and August (the mid-growing season). Maximum differences between the lowest $J_{s}\left(J_{s, 1}\right.$ or $\left.J_{s, 8}\right)$ and the highest $J_{s}\left(J_{s, 3}\right.$ or $\left.J_{s, 5}\right)$ from May through October were $12.41,17.35,16.30,18.52,12.60$ and $16.04 \mathrm{~g} /\left(\mathrm{cm}^{2} \cdot \mathrm{h}\right)$, respectively. The time-dependent changes of $J_{s}$ along the radial profile (except at $1-\mathrm{cm}$ depth) were strongly related to the reference evapotranspiration $\left(E T_{0}\right)$. Due to significant radial variability of $J_{s}$, the mean daily sap flow at the whole-tree level could be over-estimated by up to $29.69 \%$ when only a single probe at depth of $2 \mathrm{~cm}$ was used. However, the accuracy of the estimation of sap flow in Xinjiang poplar could be significantly improved using a correction coefficient of 0.885 .
\end{abstract}

Keywords: sap flow; radial pattern; Populus alba L. var. pyramidalis; reference evapotranspiration $\left(E T_{0}\right)$; Granier method

Citation: HongZhong DANG, TianShan ZHA, JinSong ZHANG, Wei LI, ShiZeng LIU. 2014. Radial profile of sap flow velocity in mature Xinjiang poplar (Populus alba L. var. pyramidalis) in Northwest China. Journal of Arid Land, 6(5): 612-627. doi: 10.1007/s40333-014-0007-7

Sap flow measurement is widely used to assess water flux at the tree-level scale in eco-hydrology. It has the advantages, over eddy covariance and inflow-outflow watershed balance, of being applicable for complex field terrain and mixed stands (Nourtier et al., 2011). Sap flow over the course of a minute, an hour or a day is often used to determine the total transpiration, which is a key variable affecting plant survival in arid and semi-arid regions. However, the presence of radial variations of sap flow velocity $\left(J_{\mathrm{s}}\right)$ in the xylem of ring-porous and diffuse-porous species can lead to biased measurement when scaling from point samples to a whole tree (Hatton et al., 1995; Gartner et al., 2005). Biased measurement is usually caused by

*Corresponding author: HongZhong DANG (E-mail: hzdang@caf.ac.cn)

Received 2013-08-02; revised 2013-11-29; accepted 2014-01-15

(C) Xinjiang Institute of Ecology and Geography, Chinese Academy of Sciences, Science Press and Springer-Verlag Berlin Heidelberg 2014 
over-estimation when point sampling only in the outer parts of the xylem and under-estimation when point sampling only in the inner parts (Čermák and Nadezhdina, 1998). Measurement discrepancy may range from $-90 \%$ to $+300 \%$ of actual transpiration if this variability is overlooked (Nadezhdina et al., 2002; Delzon et al., 2004; Ford et al., 2004a; HernándezSantana et al., 2008). Such discrepancy is particularly significant for trees of large sizes. Therefore, a well-defined radial profile of $J_{s}$ will not only help present a clear picture of the wood anatomy, the relationships between $J_{s}$ and the layout of canopy and roots (Nadezhdina et al., 2002), but also will decrease the bias produced during integrating and scaling from point sampling to a whole tree (Jiménez et al., 2000).

As previously reported, decreasing and peak patterns are the two most common radial patterns of $J_{s}$ (Hunt and Beadle, 1998; Lu et al., 2000; Wullschleger and King, 2000; Delzon et al., 2004; Nadezhdina et al., $2007 \mathrm{a}$ ). Decreasing radial patterns of $J_{s}$ in the outer xylem of a tree is usually several folds higher than that in the inner xylem of a tree (Horna et al., 2011); whereas the peak patterns of $J_{s}$ usually appear just under the cambium (i.e. approximately 1 to $3 \mathrm{~cm}$ below the cambium; Gartner et al., 2005), and then decrease quickly as depth increases. However, not all situations follow this rule. In some trees, the sap flow in the inner radial ring can account for up to $60 \%$ of the total (Poyatos et al., 2007), or a percentage similar to contribution in the outer radial ring (Phillips et al., 1996). For some specific tree species, the radial patterns of $J_{\mathrm{s}}$ may also vary within individual trees (Kumagai et al., 2007; Poyatos et al., 2007; Gebauer et al., 2008), among tree sizes (Wullschleger et al., 2001; Delzon et al., 2004) and different time of day (Cohen et al., 2008; Saveyn et al., 2008), and between different habitats (Saveyn et al., 2008). Previous report (Gartner et al., 2005) has indicated that the radial patterns of $J_{s}$ are highly variable and do not present a clear relationship to tree species or tree size. Particularly, the radial pattern of $J_{\mathrm{s}}$ for Xinjiang poplar (Populus alba L. var. pyramidalis), a widely planted tree species for farmland shelterbelts in arid regions in Northwest China, is still unknown. Multiple point measurements of $J_{s}$ through the length of the xylem are believed to provide a more reliable description of radial variability of $J_{s}$.
Xinjiang poplar has numerous notable ecological characteristics, such as being thermophilic, lightliking, wind-sheltering, rapid-growing and pest-insect resistant (Xu et al., 2011). However, the planting of these tree species in arid areas usually lead to controversial debates due to its high water requirement (Solomon, 2007). Current study monitored the $J_{S}$ of Xinjiang poplar continuously using thermal dissipation method, in order to: (1) obtain the radial distribution function of $J_{s}$ and determine the general radial pattern of $J_{s}$, as well as its diurnal and monthly variations; and (2) calculate the range of estimation error caused by single point measurements, and provide a correction coefficient to simplify the accurate estimation for sap flow of a whole tree from a point sample.

\section{Materials and methods}

\subsection{Study area and species sampling}

The experiment was conducted at Gansu Minqin National Studies Station for Desert Steppe Ecosystem $\left(103^{\circ} 05^{\prime} \mathrm{E}, 38^{\circ} 38^{\prime} \mathrm{N}\right.$; $1,367 \mathrm{~m}$ asl; Fig. 1), which is located in the lower part of the Shiyang River Basin. The southeast border of the site is adjacent to the Tengger Desert and the northwest border is in close proximity to the Badain Jaran Desert. The study area is characterized by a temperate continental desert climate with remarkable differences in inter-diurnal temperature. The annual mean temperature of the study site is $7.75^{\circ} \mathrm{C}(1961-2008)$, with the lowest temperature of $-32.2^{\circ} \mathrm{C}$ recorded in 2008 and the highest temperature of $41.0^{\circ} \mathrm{C}$ recorded in 1997 (Chang et al., 2011). The Minqin Oasis has an average annual precipitation of $113.2 \mathrm{~mm}$, an underground water level of less than $15 \mathrm{~m}$, an annual accumulated sunshine hour of 2,799.4 $\mathrm{h}$ and an active accumulated temperature $\left(\geq 10^{\circ} \mathrm{C}\right)$ of $3,036.4^{\circ} \mathrm{C}$. Similar to other typical sandy regions, the oasis experiences wind-blown sand weather up to 83 days per year. The study site has annual average wind speed of $2.5 \mathrm{~m} / \mathrm{s}$, with a maximum wind speed of $23.0 \mathrm{~m} / \mathrm{s}$ generally recorded in the spring and winter. Zonal soil of the study location is characterized as either gray or gray-brown desert soil, with poor fertility and $0.146 \%$ salt content, $0.1975 \%$ organic matter, $0.0079 \%$ total nitrogen and $\mathrm{pH}$ of 8.32 (Guo et al., 2011). The shelterbelt shrubs of Haloxylon 
ammodendron (C. A. Meyer) Bunge, which contributed to the sand-fixing in the $1960 \mathrm{~s}$, are experiencing serious degradation due to overexploitation of underground water. However, the shelterbelt forests planted along with poplar trees are in better condition due to periodical irrigation from Shiyang River water, which originates from the Qilian Mountains.

The oasis shelterbelt forests were planted in line or mesh-like structures with small grids and narrow belts, i.e. 2-4 rows with a grid area of $2.5-6.0 \mathrm{hm}^{2}$ were arranged based on the shape of farmland plot, road or drainage. The area planted with poplar trees accounts for more than $68.2 \%$ of the total shelterbelt forests area. Other trees, such as Elaeagnus angustifolia, were only planted on the fringes of drains.

Xinjiang poplar trees were usually planted in spacing of $2 \mathrm{~m} \times 5 \mathrm{~m}$ in the form of east-west oriented rows. In this study, three sampled 32-year-old Xinjiang poplar trees with no apparent scars were selected from an area of $40 \mathrm{hm}^{2}$ to measure sap flow. Data were collected from May to October 2011. The stem diameter at breast height $(\mathrm{DBH})$ and tree height were measured with a diameter tape and an altimeter, respectively. All the trees with sap flow sensors were cored with a Pressler increment borer at breast heights to determine the widths of bark, phloem, sapwood, heartwood and pith using a Vernier caliper based on visual wood color (Kravka et al., 1999). The sapwood areas were calculated at the end of the experiment. Table 1 presents the biometric parameters (i.e. stem diameter, tree height and sapwood area) of the three sampled trees.

\subsection{Meteorological data and reference evapotran- spiration $\left(E T_{0}\right)$}

Meteorological parameters, such as net radiation, air temperature, relative humidity, wind speed, wind direction and precipitation, were collected from the corresponding sensors (Avalon Scientific, Inc. USA) mounted on an automatic weather station (AR5) at a height of $2 \mathrm{~m}$. The weather station was positioned in an open area about $50 \mathrm{~m}$ away from the measured trees. The parameters were taken at 10 -s intervals and recorded every $10 \mathrm{~min}$ by a 32-channel data logger (Squirrel SQ2020, Grant Instrument Ltd., UK).

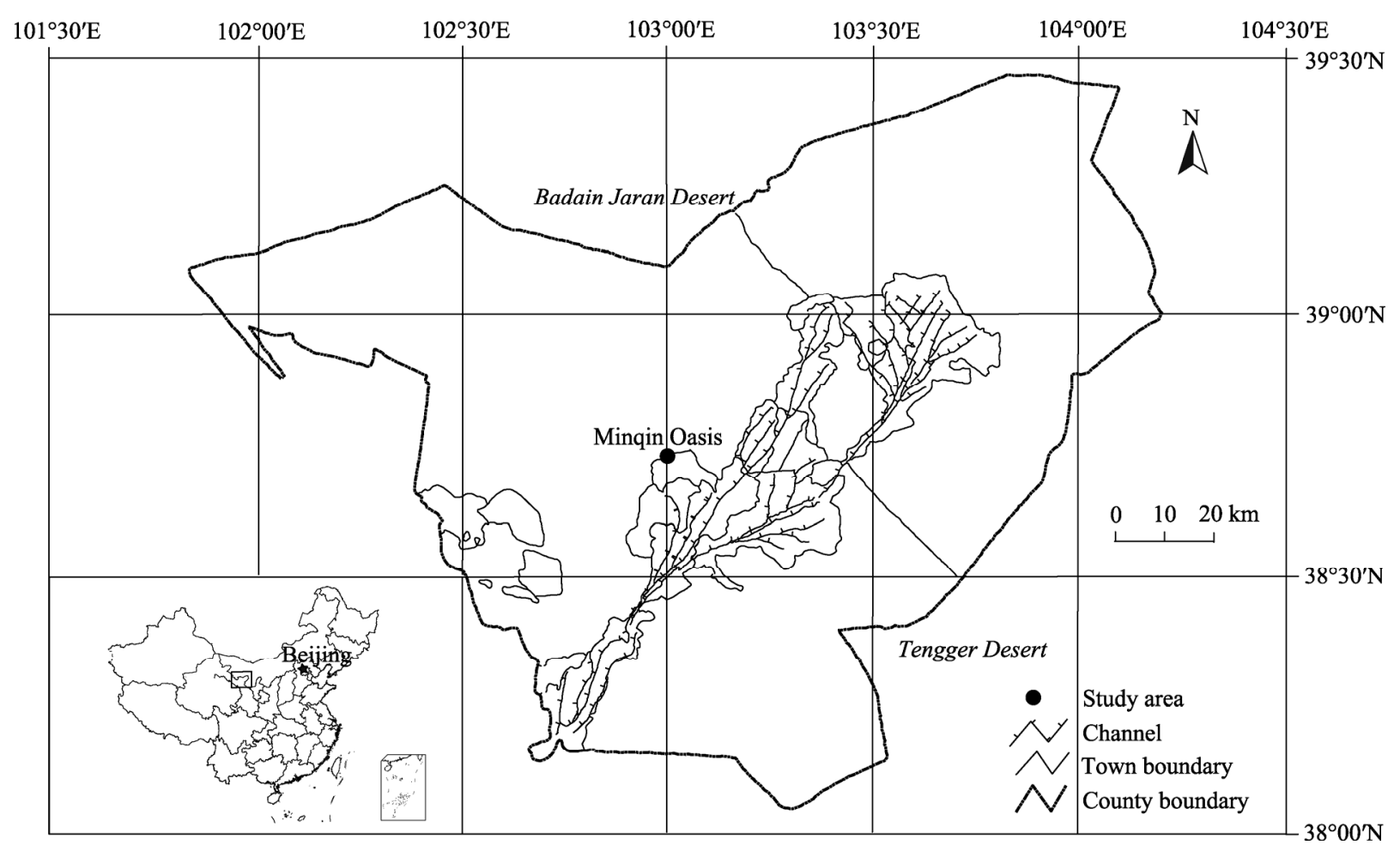

Fig. 1 Map of the study area 
Table 1 Biometric parameters of the three sampled trees selected for sap flow measurement

\begin{tabular}{|c|c|c|c|c|c|c|c|}
\hline \multirow{2}{*}{ Tree number } & \multirow{2}{*}{$\begin{array}{l}\mathrm{DBH} \\
(\mathrm{cm})\end{array}$} & \multirow{2}{*}{$\begin{array}{l}\text { Height } \\
\text { (m) }\end{array}$} & \multicolumn{4}{|c|}{ Width $(\mathrm{cm})$} & \multirow{2}{*}{$\begin{array}{c}\text { Sapwood area } \\
\left(\mathrm{cm}^{2}\right)\end{array}$} \\
\hline & & & Pith & Bark and phloem & Heartwood & Sapwood & \\
\hline Tree 1 & 30.88 & 15.24 & 0.50 & 0.33 & 7.29 & 7.33 & 527.57 \\
\hline Tree 2 & 31.20 & 15.32 & 0.50 & 0.33 & 7.36 & 7.41 & 538.45 \\
\hline Tree 3 & 30.04 & 15.16 & 0.50 & 0.31 & 7.10 & 7.11 & 498.33 \\
\hline
\end{tabular}

Note: Sapwood area was calculated based on the measured widths of bark, phloem, sapwood, heartwood and pith. DBH, diameter at breast height.

Reference evapotranspiration $\left(E T_{0}\right)$, defined as the evapotranspiration of a hypothetical grass reference crop that is well-watered, $0.12 \mathrm{~m}$ tall, actively growing and completely shading the ground (Allen et al., 1998), is widely used to determine the actual evapotranspiration (Pereira et al., 2006). We calculated daily $E T_{0}(\mathrm{~mm} / \mathrm{d})$ by using the Food and Agriculture Organization (FAO) 56 Penman-Monteith equation (Eq. 1) (Allen et al., 1998) basing on meteorological factors provided by the abovementioned automatic weather station.

$$
E T_{0}=\frac{0.408 \Delta\left(R_{n}-G\right)+\gamma \frac{900}{T+273} u_{2}\left(e_{s}-e_{a}\right)}{\Delta+\gamma\left(1+0.34 u_{2}\right)} .
$$

Where $E T_{0}$ is the reference evapotranspiration $(\mathrm{mm} / \mathrm{d})$, $\Delta$ is the slope of the saturation water vapor pressure at air temperature $T\left(\mathrm{kPa} /{ }^{\circ} \mathrm{C}\right), R_{n}$ is the net radiation $\left(\mathrm{MJ} / \mathrm{m}^{2}\right), G$ is the soil heat flux $\left(\mathrm{MJ} / \mathrm{m}^{2}\right), \gamma$ is the psychrometric constant $\left(\mathrm{kPa} /{ }^{\circ} \mathrm{C}\right), u_{2}$ is the mean wind speed at 2-m height $(\mathrm{m} / \mathrm{s}), e_{s}$ is the saturation vapor pressure $(\mathrm{kPa})$, and $e_{a}$ is the actual vapor pressure $(\mathrm{kPa})$. The calculation procedures of the parameters $R_{n}, G, e_{s}$, $e_{a}, \Delta$ and $\gamma$ were described in Allen et al. (1998).

\subsection{Measurements of sap flow velocity $\left(J_{s}\right)$}

Measurements of $J_{s}$ were carried out with Granier's thermal dissipation probe (TDP) (Granier, 1985, 1987), a technique commonly used to monitor the $J_{s}$ of trees (Iida and Tanaka, 2010; Chen et al., 2011). Probes were constructed in a manner similar to the original Grainer's design which with a pair of heated and reference needles that contain a copper-constantan thermocouple (Granier, 1987; Steppe et al., 2010). Both needles were sealed with low viscosity epoxy to make them waterproof, and were kept $10 \mathrm{~cm}$ away from each other to avoid thermal interference. The upper needle of the probe was supplied with constant electricity of $0.2 \mathrm{~W}(0.15 \mathrm{~W}$ for TDP- $1 \mathrm{~cm})$ through the $12 \mathrm{~V}$ battery storage and solar panels, whereas the lower needle served as a temperature reference. Copper-constantan thermocouples placed at the tip of the $2 \mathrm{~cm}$ long heating coil ( $1 \mathrm{~cm}$ long for TDP-1 cm) were used to measure temperature differences at 30-s intervals. The differences were recorded at $10-\mathrm{min}$ intervals (average value) by a 64-channel data logger (Squirrel SQ2040, Grant Instrument Ltd., UK). The records were then converted into $J_{s}$ using the empirical calibration equation (Granier, 1985).

Variable length probe sets (James et al., 2002; Meinzer et al., 2004; Herbst et al., 2008) were adopted and installed at breast height $(1.3 \mathrm{~m})$ to measure $J_{s}$ at five depths (i.e. 1, 2, 3, 5 and $8 \mathrm{~cm}$ under the cambium) in the xylem. Probes pairs were placed $10 \mathrm{~cm}$ apart in both vertical and circumferential directions (Fig. 2). Probes at the outermost position were installed on the north side of the stem to minimize direct heat from sunlight. Subsequent probes were then installed clockwise and in an upward spiral direction around the stem at $45^{\circ}$ intervals (Gonzalez-Benecke et al., 2011). All the probe sets were shielded against sunlight with aluminum foil and sealed at the top to prevent rain damage.

Natural temperature gradient, described as one of the error sources in Granier's system (Do and Rocheteau, 2002), was negligible in this study because it was found to be consistently less than $0.2^{\circ} \mathrm{C}$ along the trunk when the probes were at non-heated state. The original empirical equation for $J_{s}$ was adopted as Eq. 2 .

$$
J_{s}=119 \times K^{1.231} .
$$

Where $K$ is the temperature constant. $K$ can be expressed as Eq. 3.

$$
K=\left(\frac{\Delta T_{0}-\Delta T}{\Delta T}\right) .
$$

Where $\Delta T$ is the actual temperature difference observed between the heated and the reference needles; and $\Delta T_{0}$ is the maximum $\Delta T$ when $J_{s}$ is the lowest, the value of $\Delta T_{0}$ is determined based on measurements taken on 10 consecutive days (Lu et al., 2004). 


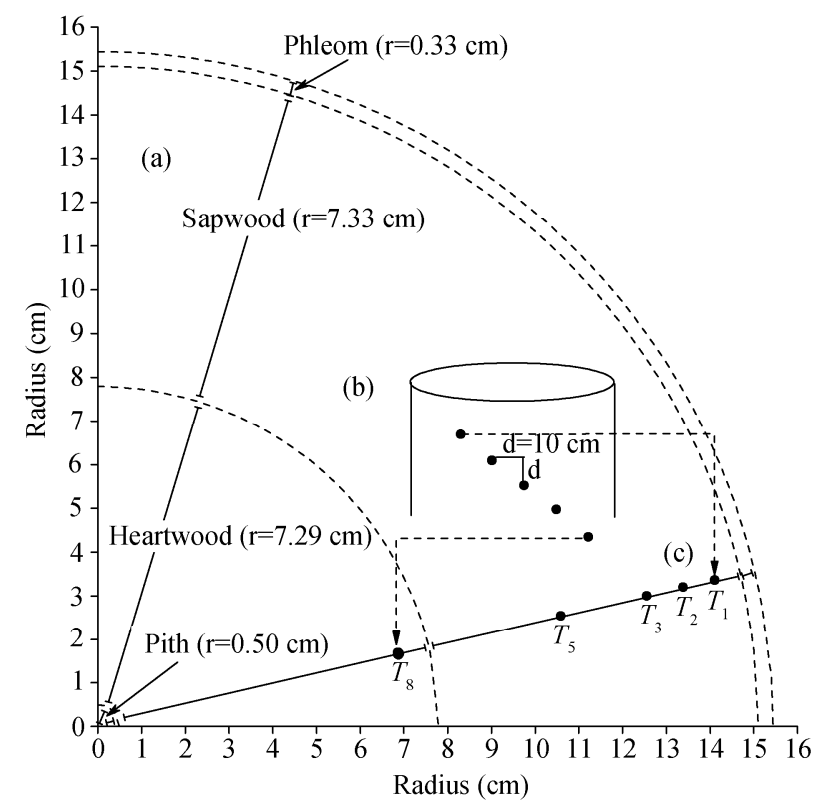

Fig. 2 A schematic diagram of the layout of sap flow probes. (a) Xylem structure, pith width, and radius of heartwood, sapwood and phloem. (b) Layout of probes on the trunks. Each probe pair was placed $10 \mathrm{~cm}$ apart $(\mathrm{d}=10 \mathrm{~cm})$ in both axial and circumferential directions to decrease potential thermal interference between probes. Probe $T_{8}$ was installed at breast height $(1.3 \mathrm{~m})$. Probe pairs installed from the north-facing side of the trunk were designed to minimize direct radiation. (c) Depths of probes in the xylem after bark removal. $T_{1}, T_{2}, T_{3}, T_{5}$ and $T_{8}$ represent the locations where the probes were installed at the depths of 1,2, 3, 5 and $8 \mathrm{~cm}$ under the cambium, respectively. All probes were arranged in a half circle sector in the circumferential direction. The placement of the probes made it possible to ignore the bias produced in the azimuthal and axial directions for tall trees.

\subsection{Statistical analyses}

All the data were collected from May to October (the mid of the growing season) 2011, and were fitted to the following four-parameter GaussAmp equation to describe the distribution of $J_{s}$.

$$
J_{s}=J_{s, 0}+\alpha e^{-0.5\left(\frac{d-d_{0}}{\beta}\right)^{2}} .
$$

Where $J_{s, 0}$ is the $J_{s}$ in the outermost part of the xylem, $\alpha$ is the maximum of $J_{s}, d$ is the depth under the cambium in the xylem, $d_{0}$ is the depth in the xylem where the maximum $J_{s}$ occurs, and $\beta$ is a coefficient of the decline rate of $J_{S}$ with respect to the radial depth. Curve fitting was performed with Origin 9.0 software (OriginLab, USA).

Equation 5 shown below was used to calculate radial correction factor $\left(C_{r a d, i}\right)$ when only a pair of $2 \mathrm{~cm}$ sensors were available.

$$
C_{r a d, i}=\frac{J_{s, i}}{J_{s, r e f}} .
$$

Where $J_{s, i}$ denotes the $J_{s}$ at $i^{\text {th }}$ depth in the xylem $(i=1,3,5$ and $8 \mathrm{~cm})$, and $J_{s, r e f}$ denotes the $J_{s}$ at $2 \mathrm{~cm}$ depth $(i=2 \mathrm{~cm})$, which is the depth designed by Granier and used as the reference value.

Using Eq. 6, we calculated total sap flow $(T, \mathrm{~kg} / \mathrm{d})$, which was based on the sapwood area as determined by five probes instead of visually determined sapwood width.

$$
T=\sum_{i=1}^{5} S_{c, i} \times J_{s, i} .
$$

Where $S_{c, i}$ denotes the sapwood area corresponding with $i^{\text {th }}$ depth, and it can be calculated by the following equation.

$$
S_{c, i}=\pi \times r_{s, i}{ }^{2}-\pi \times r_{s, i-1}^{2} .
$$

Where $r_{s, i}$ is the xylem radius at $i$ th depth, and $i$ denotes the various depth sites $(i=1,2,3,5$ and $8 \mathrm{~cm})$.

\section{Results}

\subsection{Sap flow at different depths on the daily scale}

Values of daily sap flow at five depths of the xylem of the three sampled trees, as well as meteorological parameters for the same period are shown in Fig. 3. Overall, daily sap flow from the outer to the inner xylem displayed a normal-shaped trend with the actual values $($ mean $\pm \mathrm{SD})$ of $5.38 \pm 2.43,14.88 \pm 6.36$, $20.93 \pm 8.06,18.33 \pm 7.82$ and $7.55 \pm 3.83 \mathrm{~kg} /\left(\mathrm{dm}^{2} \cdot \mathrm{d}\right)$ for $J_{s, 1}, J_{s, 2}, J_{s, 3}, J_{s, 5}$ and $J_{s, 8}$, respectively. The average daily $J_{s, 3}$, from the main part of the xylem was highest from June to August, with the recorded value of 21.56-26.15 $\mathrm{kg} /\left(\mathrm{dm}^{2} \cdot \mathrm{d}\right)$, followed by $17.66 \mathrm{~kg} /\left(\mathrm{dm}^{2} \cdot \mathrm{d}\right)$ in May, 14.18 $\mathrm{kg} /\left(\mathrm{dm}^{2} \cdot \mathrm{d}\right)$ in September and $13.64 \mathrm{~kg} /\left(\mathrm{dm}^{2} \cdot \mathrm{d}\right)$ in October. $J_{s}$ at the other four depths also displayed the same trend, but of lower values. Day-to-day sap flow during the growing season could be determined in Fig. 3. The maximum daily $J_{s, 2}, J_{s, 3}, J_{s, 5}$ and $J_{s, 8}$ for the three sampled trees all occurred on 26 July, with the mean solar radiation $\left(R_{\mathrm{a}}\right)$ of $287.35 \mathrm{~W} / \mathrm{m}^{2}$, vapor pressure deficit (VPD) of $2.97 \mathrm{kpa} / \mathrm{d}$ and $E T_{0}$ of $6.27 \mathrm{~mm} / \mathrm{d}$. For examples, the maximum sap flow values of tree 3 were $25.95,29.48,41.68$ and $18.36 \mathrm{~kg} /\left(\mathrm{dm}^{2} \cdot \mathrm{d}\right)$ for $J_{s, 2}, J_{s, 3}$, $J_{s, 5}$ and $J_{s, 8}$ on $26 \mathrm{July}$, respectively. As for $J_{s, 1}$, the maximum value was recorded as $11.19 \mathrm{~kg} /\left(\mathrm{dm}^{2} \cdot \mathrm{d}\right)$ on 10 May.

\subsection{Radial profile pattern of $J_{s}$}

Radial profile pattern of $J_{\mathrm{s}}$ along the xylem in Xinjiang 
poplar followed a variable trend with the relative depth (Fig. 4). $J_{s, 1}$ was lower than $J_{s, 2}$. The $C_{r a d, 1}$ values were found to be only $35 \%, 44 \%$ and $29 \%$ for trees 1,2 and 3 , respectively. Compared to $J_{s, 1}, J_{s, 2}$ increased rapidly to $15.47 \pm 6.50,15.03 \pm 6.44$ and $14.14 \pm 6.12 \mathrm{~kg} /\left(\mathrm{dm}^{2} \cdot \mathrm{d}\right)$ for trees 1,2 and 3, respectively. In the original G-system, $J_{s, 2}$ values were considered as the standard values (Granier, 1985). $J_{s, 3}$ for trees 1 and 2 and $J_{s, 5}$ for tree 3 were shown to be the single-peak points of radial variation of $J_{\mathrm{s}}$, and were of considerably higher values than the other $J_{\mathrm{s}}$. The peak of $C_{\text {rad, } 3}$ reached $137 \%$, $164 \%$ for both trees 1 and 2 , while $C_{\text {rad, } 5}$ reached $167 \%$ for tree 3. Sap flow velocity was found to decrease gradually after depth at $3 \mathrm{~cm}$, and $C_{r a d, 8}$ values of the innermost measured points were only of $34 \%, 39 \%$ and $82 \%$ for trees 1,2 and 3 , respectively.

To further characterize the radial patterns of $J_{s}$ in Xinjiang poplar, the relationship between $J_{s}$ and $r_{d}$ (the ratio of depth to radius) was determined using Eq. 4. The results showed that $J_{s}$ along the radial xylem of Xinjiang poplar varied and exhibited a Gaussian pattern with a single peak (Fig. 4). However, the positions of peaks among the three sampled trees were different even though their DBHs, heights and ages were very similar (Table 1). The dependence of $J_{s}$ on the relative depth of the xylem fitted well with the four-parameter
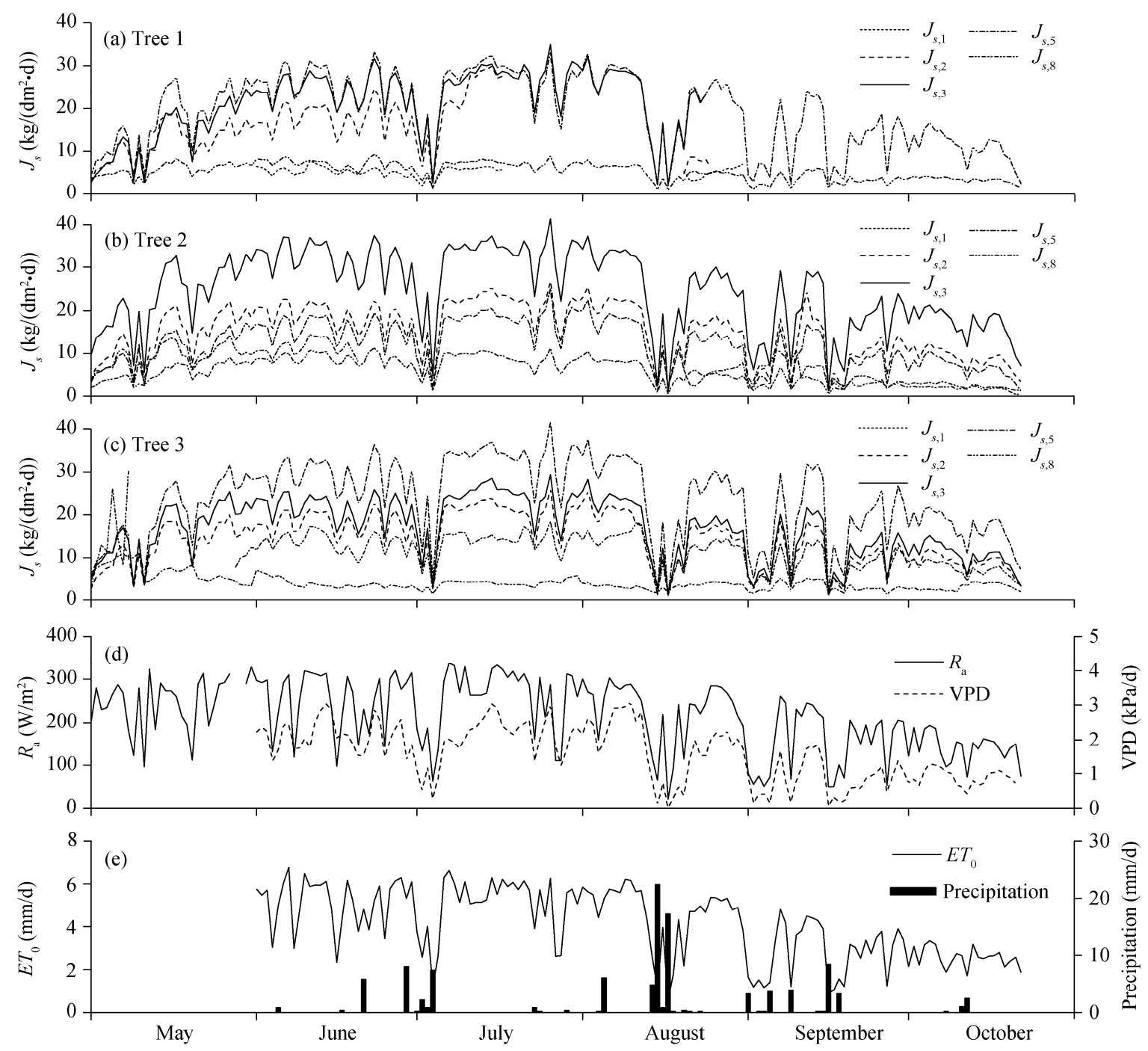

Fig. 3 Daily variation in sap flow and meteorological parameters. Trunk sap flow velocity $\left(J_{s}\right)$ at different depths of the xylem in Xinjiang poplar, solar radiation $\left(R_{\mathrm{a}}\right)$, vapor pressure deficit (VPD), precipitation, and reference evapotranspiration $\left(E T_{0}\right)$ from May to October 2011. $J_{s, 1}, J_{s, 2}, J_{s, 3}, J_{s, 5}$ and $J_{s, 8}$ represent $J_{s}$ at depths of $1,2,3,5$ and $8 \mathrm{~cm}$ of the xylem, respectively. Some daily data were excluded due to incomplete hourly data. 


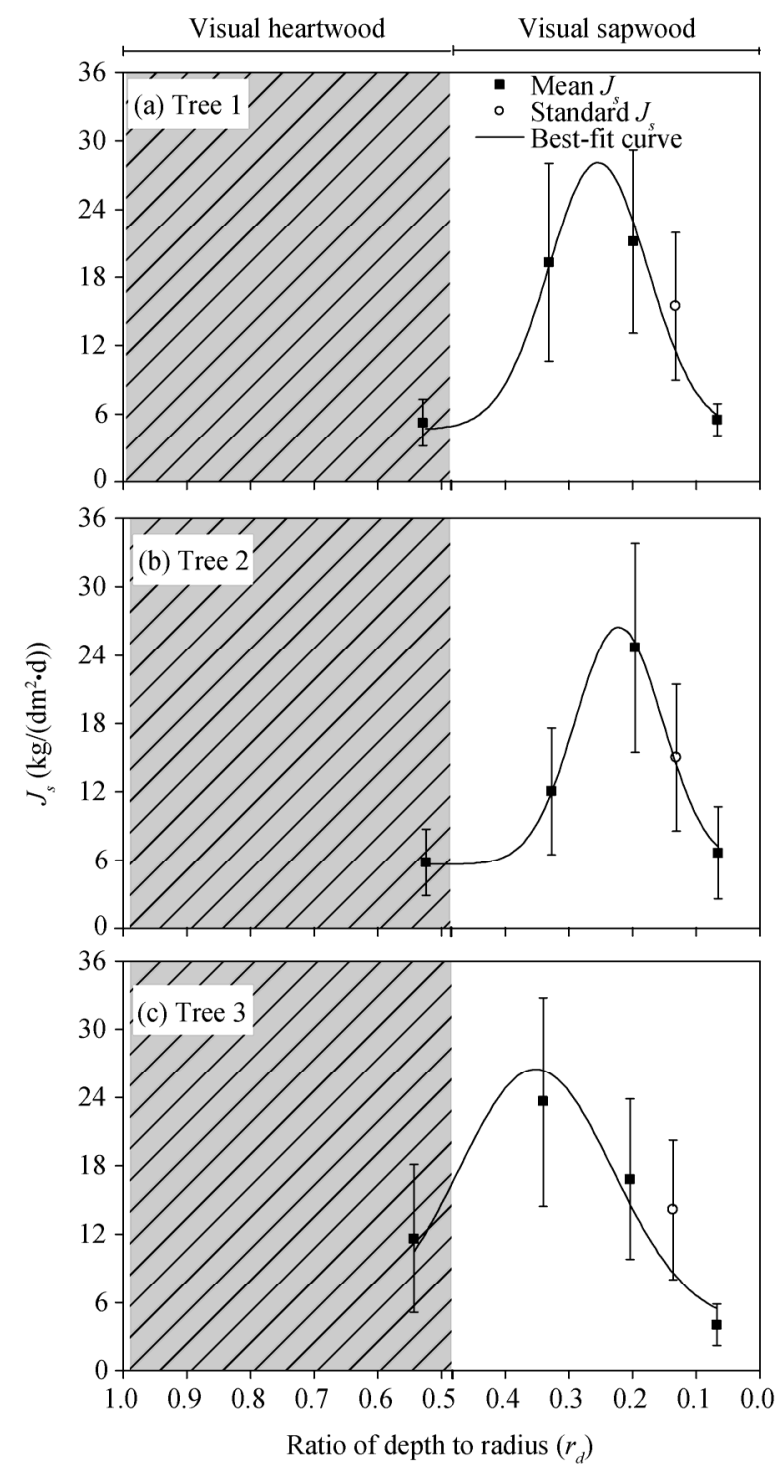

Fig. 4 Radial variations of $J_{\mathrm{s}}$ through the xylem of the three sampled trees. Solid boxes represent the mean $J_{s}$ at depths of 1 , 3,5 and $8 \mathrm{~cm}$ of the xylem (from right to left, respectively), open circles denote the $J_{s}$ at 2-cm depth as the standard value, vertical bars indicate the standard errors, and solid lines represent the best-fit curves calculated using the GaussAmp equation. Shaded grey squares indicate the visual location of the heartwood-sapwood interfaces, which were determined based on the tree cores. All the data were collected from a survey that lasted for 174 days from May to October 2011 (excluding the days with missing valid data due to power-off).

Table 2 Values used to calculate the radial pattern of $J_{s}$ with the GaussAmp equation

\begin{tabular}{cccccc}
\hline Tree number & $\alpha$ & $\beta$ & $d_{0}$ & $J_{s, 0}$ & $R^{2}$ \\
\hline Tree 1 & 23.503 & 0.078 & 0.254 & 4.611 & 0.72 \\
Tree 2 & 20.826 & 0.069 & 0.222 & 5.633 & 0.97 \\
Tree 3 & 22.455 & 0.121 & 0.352 & 4.034 & 0.66 \\
\hline
\end{tabular}

GaussAmp equation (Eq. 4). Such correlation was characterized by the peak which was within the scope of 0.22 to 0.35 radius. The maximum of $J_{s}(\alpha)$ ranged from 20.826 to $22.455 \mathrm{~kg} /\left(\mathrm{dm}^{2} \cdot \mathrm{d}\right)$ for the three sampled trees, whereas $J_{s}$ in the outermost layer of the xylem $\left(J_{s, 0}\right)$, was only 4.034 to $5.633 \mathrm{~kg} /\left(\mathrm{dm}^{2} \cdot \mathrm{d}\right)$ (Table 2$)$.

\subsection{Diurnal variability in the radial profile of $J_{\mathrm{s}}$}

Diurnal course of the radial profile of $J_{\mathrm{s}}$ reflected the changes at each depth and the overall pattern through the radial xylem (Fig. 5). In general, the diurnal course of $J_{\mathrm{s}}$ at each depth followed a nearly normal-shaped curve. That is, sap flow started at sunrise, increased rapidly with the increase of solar radiation $\left(R_{\mathrm{a}}\right)$ (the diurnal course of $R_{\mathrm{a}}$ was not shown in this paper), and reached its peak at 14:00 to 15:00. Sap flow then declined in the afternoon with the decrease of $R_{\mathrm{a}}$ and remained relatively weak until midnight.

In fact, sap flow was so weak during the nighttime period (22:00 to 06:00) that it was difficult to distinguish the differences of $J_{s}$ at different depths. Sap flow during this period followed a nearly line-shaped radial pattern. The mean hourly $J_{s}$ during this period was only 0.33 to $0.82 \mathrm{~g} /\left(\mathrm{cm}^{2} \cdot \mathrm{h}\right)$, with standard deviation of less than $0.39 \mathrm{~g} /\left(\mathrm{cm}^{2} \cdot \mathrm{h}\right)$, which is a value generally considered as water recharge or nocturnal transpiration. However, during the day (07:00 to 19:00), $J_{s}$ at each depth started to increase shortly after sunrise (at about 07:00). It then surged rapidly until 12:00, and remained at a high level until it reached its peak at 15:00. $J_{s, 5}$, as one of the fastest increasing sap flow, escalated from 0.68 to $24.37 \mathrm{~g} /\left(\mathrm{cm}^{2} \cdot \mathrm{h}\right)$ within ten hours (06:00 to 15:00) and showed the higher amplitude. Standard deviation of $J_{s}$ among the five depths at 15:00 was as high as $9.71 \mathrm{~g} /\left(\mathrm{cm}^{2} \cdot \mathrm{h}\right)$ and followed a clear radial pattern in July. After then, $J_{s}$ at each depth declined gradually at different rate, and the standard deviation of $J_{s}$ among the five depths at 21:00 was only $2 \%$ of that at 15:00.

\subsection{Monthly variability in the radial profile of $J_{\mathrm{s}}$}

Aside from diurnal variability, the monthly variability in the radial profile of $J_{s}$ for Xinjiang poplar showed a typical variation trend as well (Fig. 6). $J_{s, 3}$ and $J_{s, 5}$, being at the depths most important for water transport in the xylem, had higher amplitudes among the five depths during the day. Both $J_{s, 3}$ and $J_{s, 5}$ increased rapidly and remained at higher levels for longer period of 
time at around midday. $J_{s, 2}$, a reference standard sap flow used by the G-system, was lower than $J_{s, 3}$ and $J_{s, 5}$, while $J_{s, 8}$ and $J_{s, 1}$ had the least amplitudes of the five different $J_{s,}$. The peaks of $J_{s}$ were wider and more noticeable from June to August. This contributed to the different monthly variability patterns in the radial profile of $J_{s}$. June to August is the major growing season in northern China. This period has stronger $R_{\mathrm{a}}$ and higher air temperature. However, the patterns of the radial profiles of $J_{s}$ for the rest of the study period showed lower overall values and less pronounced peaks. The differences between the lowest $J_{s}\left(J_{s, 1}\right.$ or $\left.J_{s, 8}\right)$ and the highest $J_{s}\left(J_{s, 3}\right.$ or $\left.J_{s, 5}\right)$ for May to October were $12.41,17.35,16.30,18.52,12.60$ and $16.04 \mathrm{~g} /\left(\mathrm{cm}^{2} \cdot \mathrm{h}\right)$, respectively. $J_{s, 8}$, which is recorded at the innermost point of the xylem at $8-\mathrm{cm}$ depth, maintained the value of $5.93 \mathrm{~g} /\left(\mathrm{cm}^{2} \cdot \mathrm{h}\right)$ and above at midday. In addition, we found that $J_{s, 8}$ was higher than $J_{s, 1}$ for the majority of the test period. Except when in July, $J_{s, 1}$ was higher than $J_{s, 8}$, with the average value of $13.0 \mathrm{~g} /\left(\mathrm{cm}^{2} \cdot \mathrm{h}\right)$ at $14: 00$ and
$8.24 \mathrm{~g} /\left(\mathrm{cm}^{2} \cdot \mathrm{h}\right)$ at 15:00, respectively.

\subsection{Correlation between the radial profile of $J_{\mathrm{s}}$ and $E T_{0}$}

$E T_{0}$ is an effective variable used to represent the main atmospheric factors (i.e. solar net radiation, vapor pressure deficit, air temperature, air humidity and wind speed) that affect the sap flow of the trunk (Chen et al., 2014). Generally, hourly rates of sap flow closely followed the diurnal patterns of $E T_{0}$. To discern the differences of the five $J_{s}$, we fitted the data to a simple linear curve (Fig. 7). Linear regression coefficients of $J_{s}$ at depths of 2, 3, 5 and $8 \mathrm{~cm}$ were found to be greater than 0.74 . The coefficients indicated strong effects of the meteorological elements (represented by $E T_{0}$ ) on sap flow and high water-transport from the root to the canopy of Xinjiang poplar. However, we found the lower linear regression coefficients of 0.32 to 0.46 at the outer layer of the xylem at $1-\mathrm{cm}$ depth. We suspected that other factors

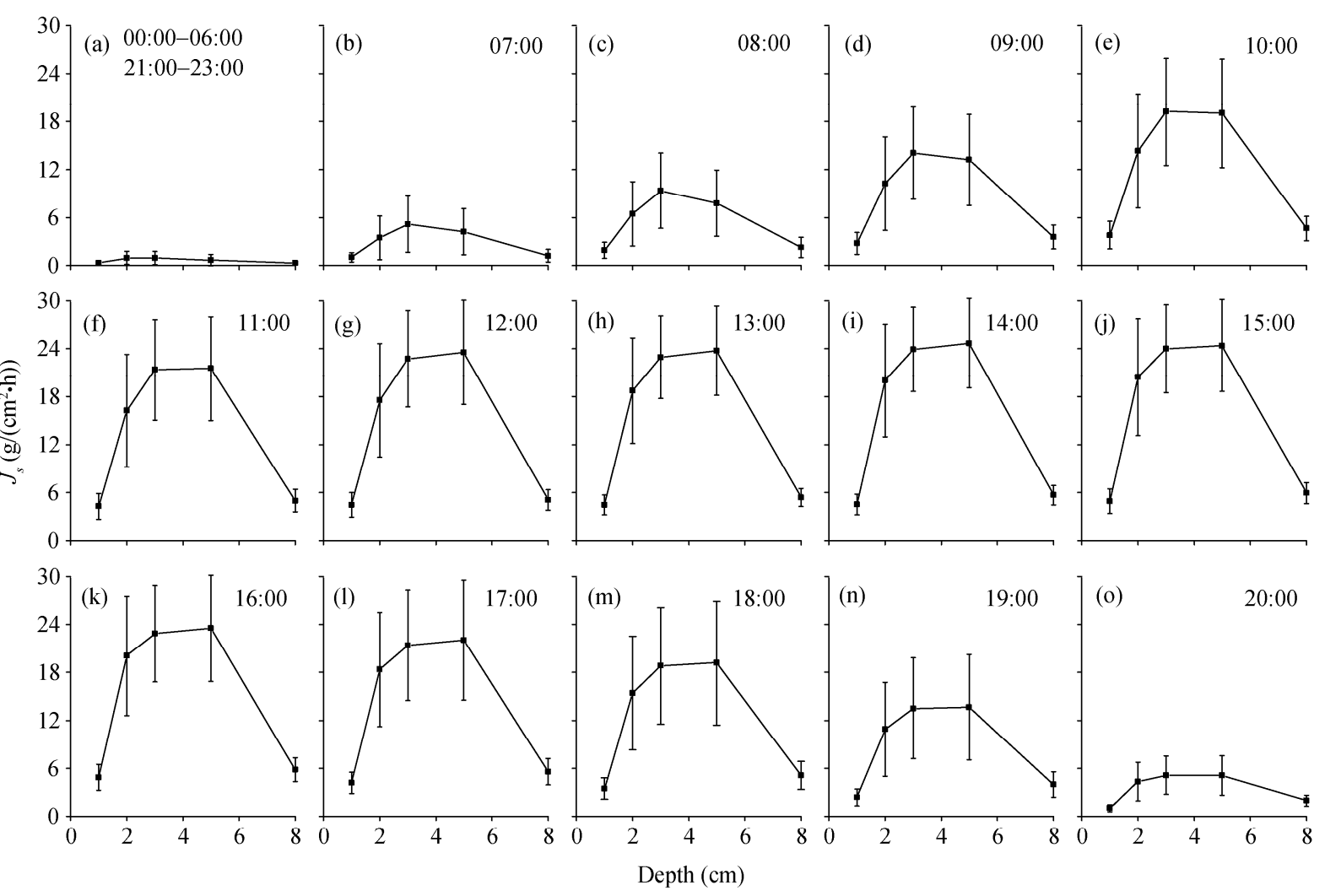

Fig. 5 Diurnal courses of radial variation of $J_{s}$ on typical sunny days in July 2011. Solid boxes and vertical lines represent the mean values and standard error bars of radial variation of $J_{s}$ within the 31 days, respectively. The course at nighttime (21:00 to 23:00 and 00:00 to 06:00) did not change significantly, so we selected 06:00 as the representative time point for nighttime. See sub figure (a) at the upper left corner. 

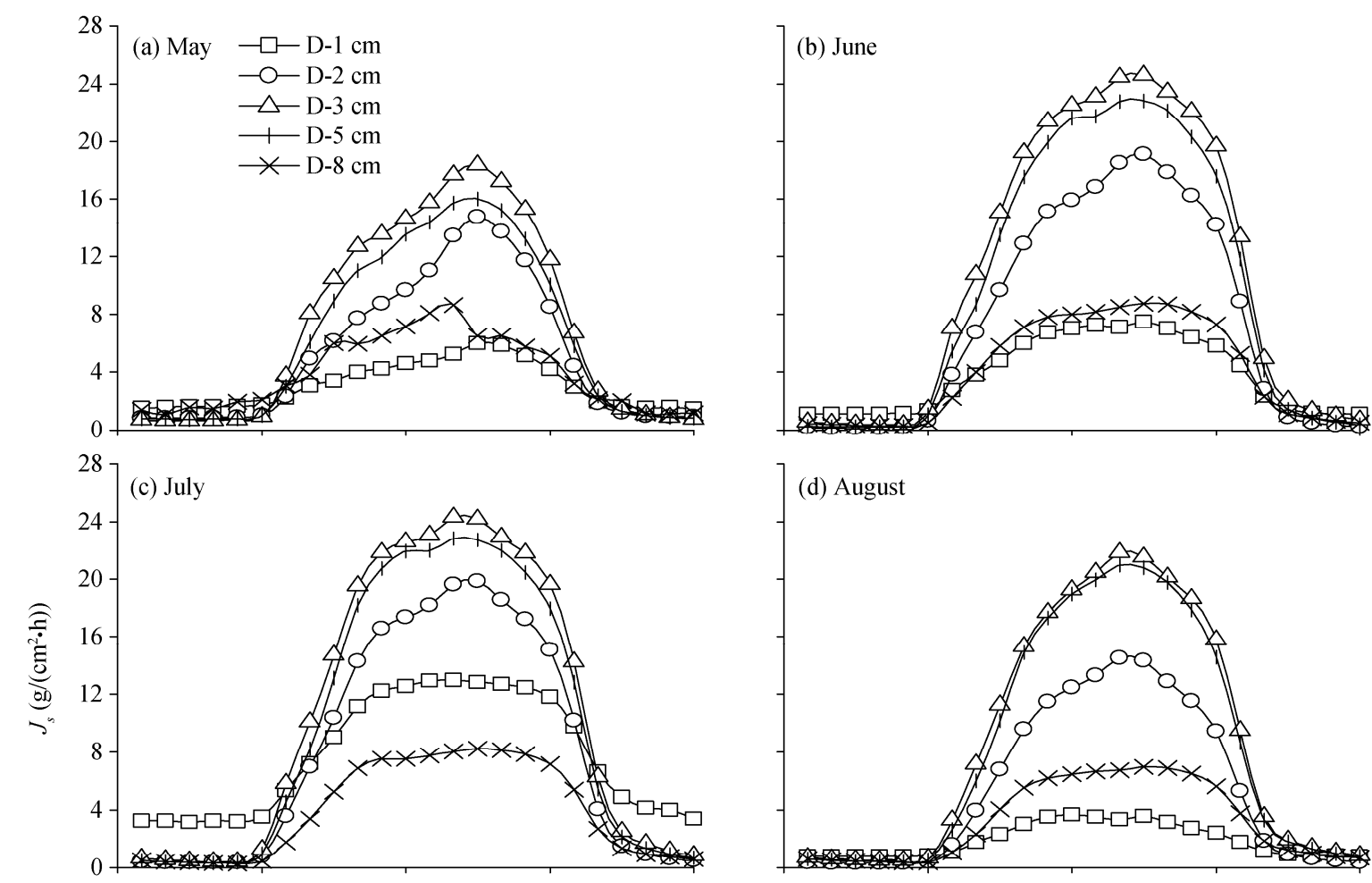

(d) August
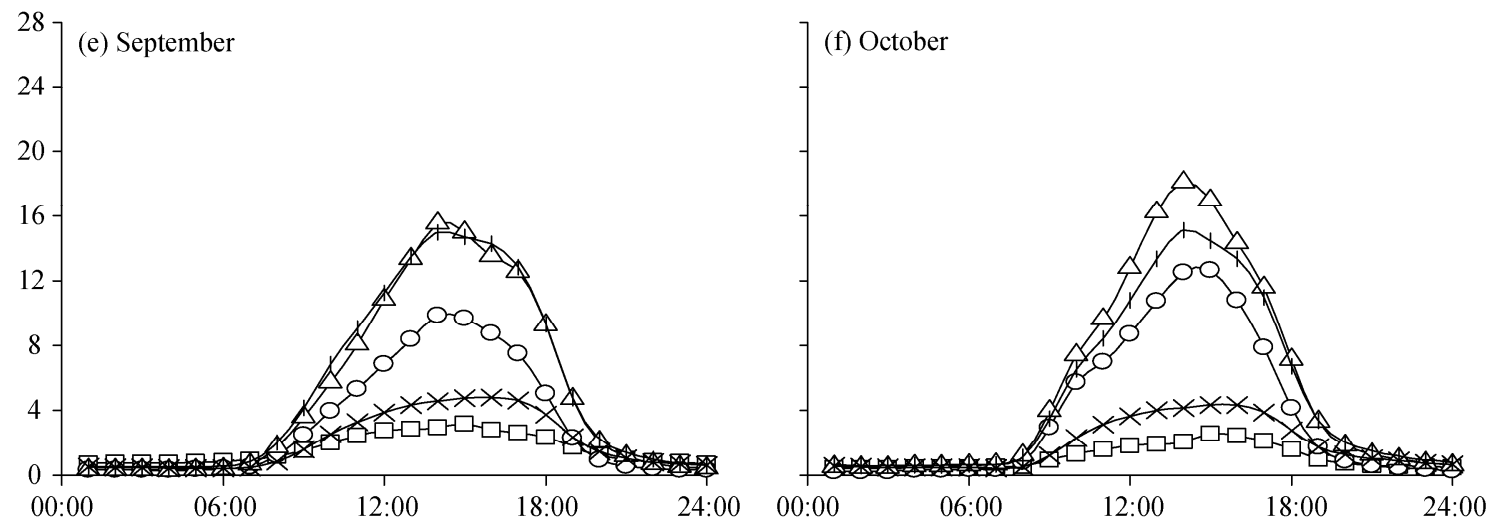

Fig. 6 Diurnal courses and patterns of radial variation of $J_{s}$ from May to October 2011. Symbols are mean $J_{s}$ values for the three sampled trees. Error bars were not shown to improve legibility. D-1, D-2, D-3, D-5 and D-8 cm denote the inward distances of 1, 2, 3, 5 and 8 $\mathrm{cm}$ from the outer xylem, respectively.

may influence the sap flow at this layer of the xylem.

\subsection{Correction coefficient of using standard $J_{s}$ to estimate sap flow at a whole-tree scale}

The radial pattern of $J_{s}$ mentioned above showed the regular pattern in the distribution of $J_{s}$, which may allow us to predict the $J_{s}$ of the other depths of xylem using a cost-effective, one point sampling method. Simple correlation analysis showed that Js,2 (the standard Js at 2-cm depth) was significantly correlated with the $J_{s}$ at other depths, as indicated by the high coefficient value (Table 3). Among the $J_{s}$ of the other depths, coefficients between $J_{s, 2}$ and $J_{s, 3}$ and between $J_{s, 5}$ and $J_{s, 8}$, were higher than those between $J_{s, 2}$ and $J_{s, 1}$, indicating that $J_{s, 2}$ can be used as a good predictor of $J_{s}$ for most sapwoods.

Regression analyses showed that the relationships between the daily sap flow measured by the reference sensor and those measured by five sensors from radial integration were always linear $\left(R^{2}=0.98\right.$ to 0.99 ; Fig. 8). During the study period, total sap flow amounts of the three sampled trees calculated by the two methods were not exactly the same (Table 4). The single point 
measurement over-estimated total sap flow by nearly $30 \%$, particularly in tree 1 and 2 . The biases of daily sap flow at the whole-tree scale for tree 1 and 2 were $17.35 \%$ and $29.69 \%$, respectively. However, for tree 3 , the results obtained by the two methods of measure- ment were similar, with only $0.56 \%$ under-estimation by the single point measurement. The slopes of the relationships between the daily sap flow calculated by the reference sensor and that of the radial integration of the three sampled trees varied from 0.769 to 0.984 ,

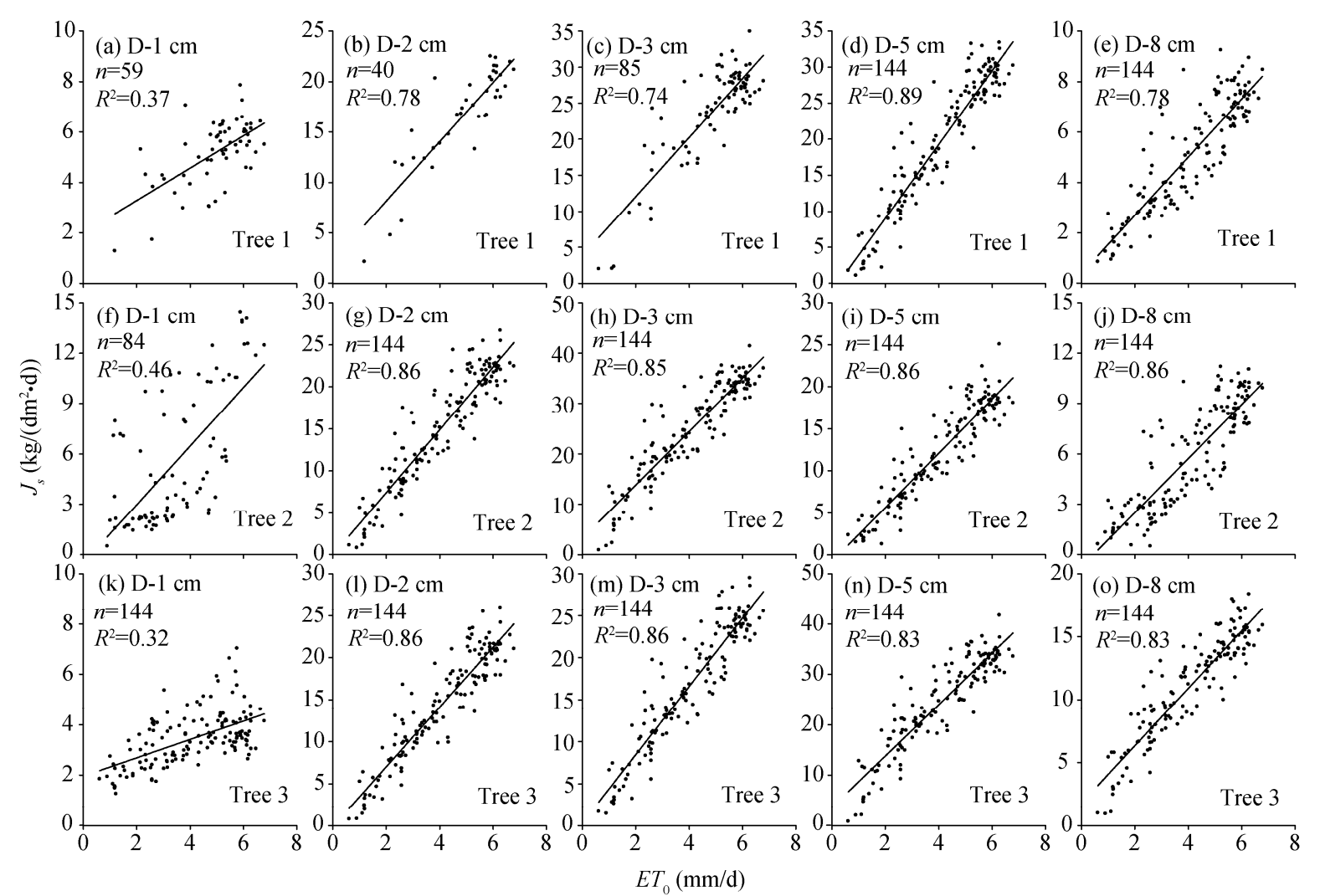

Fig. 7 Relationships between $J_{s}$ and daily $E T_{0}$ at different depths of the xylem of the three sampled trees. $n$ denotes the number of days from the start of the studied period, and $R^{2}$ is the coefficient of determination.

Table 3 Simple correlation coefficients between $J_{s}\left(\mathrm{~kg} /\left(\mathrm{dm}^{2} \cdot \mathrm{d}\right)\right)$ of standard depth $\left(T_{2}\right)$ and that of other depths $\left(T_{1}, T_{3}, T_{5}\right.$ and $\left.T_{8}\right)$

\begin{tabular}{ccccc}
\hline Tree number & $T_{1}$ & $T_{3}$ & $T_{5}$ & $T_{8}$ \\
\hline Tree 1 & 0.76 & 0.85 & 0.83 & 0.83 \\
Tree 2 & 0.67 & 0.98 & 0.99 & 0.93 \\
Tree 3 & 0.63 & 0.99 & 0.99 & 0.95 \\
\hline
\end{tabular}

Notes: Two-tailed test of significance was used. All the correlations were significant at the 0.05 level.

which showed the different sap flow radial patterns among individual trees (Figs. 4 and 8). As an attempt to simplify the calculation of sap flow at the whole-tree scale with the single point measurement, the correction coefficient of 0.885 obtained through the three sampled trees can be used for estimation without considering individual differences (Fig. 8d).

\section{Discussion}

\subsection{Patterns of sap flow along the radius of xylem}

In the majority of cases reported (i.e. Gartner et al., 2005), decreasing and peak patterns of sap flow are more common than even and erratic patterns. Sap flow is considered to be mainly concentrated in the outer part of the xylem. However, the actual contribution of sap flow at the different parts of the xylem is still unclear. In this study, the Gaussian radial pattern, a pattern that is commonly seen in coniferous species with tracheid xylem anatomy (Fiora and Cescatti, 2006), was found to conform to the radial variation pattern of $J_{s}$ in Xinjiang poplar. This is interesting because such pattern is evidently different from the previously reported patterns, such as, the declining 
radial pattern (Becker, 1996; Phillips et al., 1996; Jiménez et al., 2000; Tateishi et al., 2010), the exponential pattern (Horna et al., 2011), the Beta distribution pattern (Caylor and Dragoni, 2009), and the nearly monotonically declined pattern (Fernández et al., 2008; González-Altozano et al., 2008).

In particular, the peak of $J_{s}$, which was generally considered to lie in the outer xylem of a tree, was found to have shifted inward in Xinjiang poplar. The sap flow pattern of $J_{s}$ in Xinjiang poplar was tree-specific and varied seasonally. This is especially true for $J_{s, 1}$ and $J_{s, 8}$ in July (Fig. 5), which followed a pattern similar to the one reported by Lüttschwager and Remus (2007). Several studies surmised that shaded and suppressed trees or even-aged stands have less variable radial patterns and have low $J_{s}$, whereas dominant trees and isolated plants with long crown, and trees in sparse or discontinuous forests show apparent peak in the radial pattern and have high $J_{s}$ (Jiménez et al., 2000; Fiora and Cescatti, 2006). Our results showed that Xinjiang poplar exhibited the latter pattern.

The peak $J_{s}$ of Xinjiang poplar was found at approximately 0.22 to 0.35 radius from the outer layer of the xylem. This observation indicated that Xinjiang polar differ from some species that either exhibited peaks under the cambium (Jiménez et al., 2000) or within 1 to $3 \mathrm{~cm}$ from the cambium (Gartner et al., 2005). Previous report (Cohen et al., 2008) showed that the peak $J_{s}$ in the xylem of trees in sub-humid areas are usually below the cambium, whereas those in semi-arid or arid areas have shifted peak with steeper

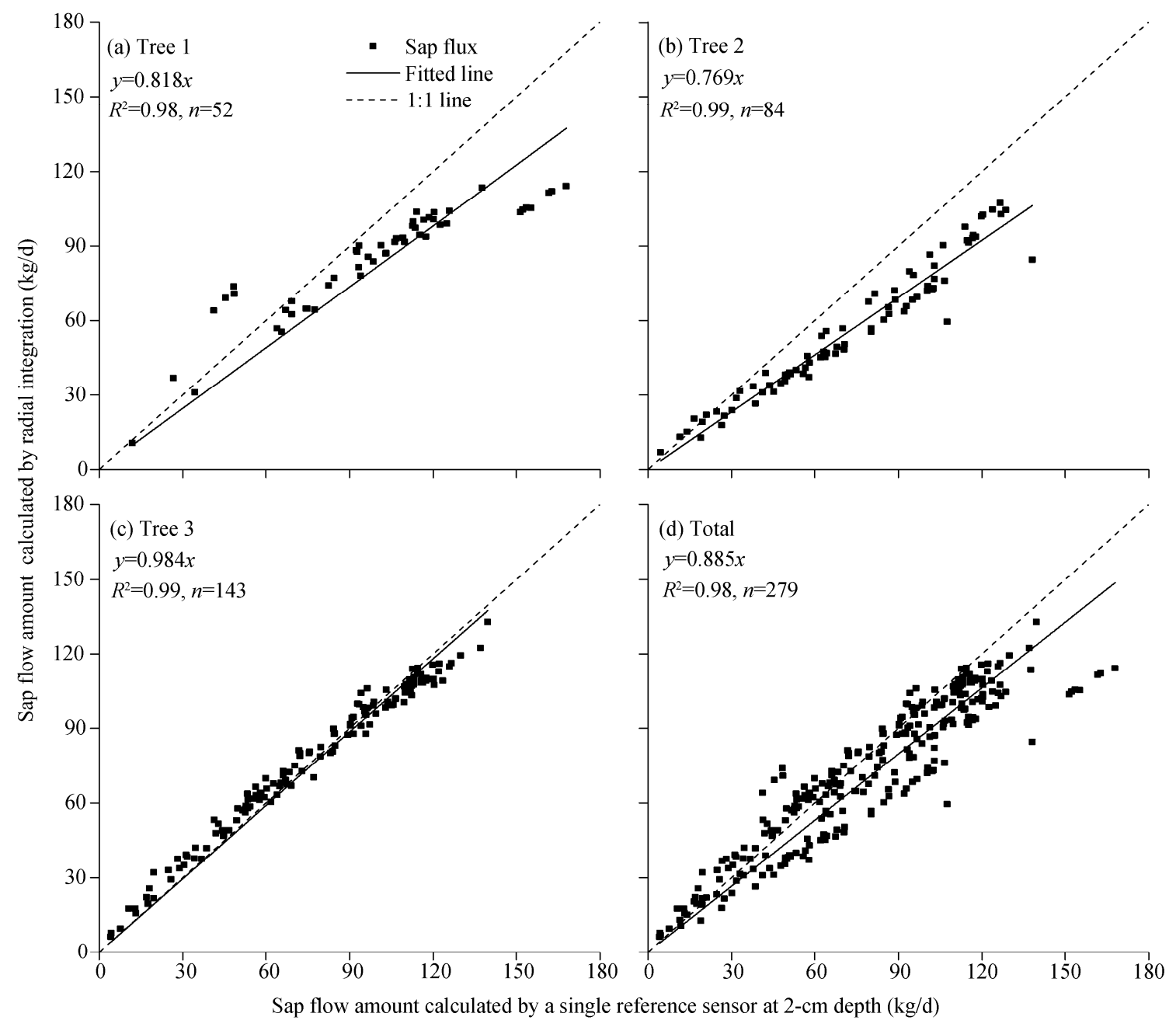

Fig. 8 Relationships between daily sap flow amount of the whole tree calculated by a reference sensor at 2-cm depth and radial integration. $n$ denotes the valid days (days were rejected as soon as one probe was broken), and $R^{2}$ is the coefficient of determination. 
Table 4 Sap flow amounts calculated by the two methods at the whole-tree scale

\begin{tabular}{cccc}
\hline Tree number & $\begin{array}{c}\text { Sap flow amount calculated by radial } \\
\text { integration }(\mathrm{kg} / \mathrm{d})\end{array}$ & $\begin{array}{c}\text { Sap flow amount calculated by a single } \\
\text { reference sensor }\left(T_{2}\right)(\mathrm{kg} / \mathrm{d})\end{array}$ & $\begin{array}{c}\text { Percentage of under-or over-estimated } \\
(\%)\end{array}$ \\
\hline Tree 1 & $84.65 \pm 21.74$ & $99.34 \pm 36.26$ & +17.35 \\
Tree 2 & $56.14 \pm 26.19$ & $72.81 \pm 33.44$ & +29.69 \\
Tree 3 & $78.24 \pm 29.80$ & $77.80 \pm 33.96$ & -0.56 \\
\hline
\end{tabular}

profiles. The middle part of the xylem, as characterized by significant diurnal fluctuations of sap flow (Figs. 4 and 5), was not consistent with the decreasing pattern described by Fiora and Cescatti (2006). We hypothesized that the low water-transport of the outer xylem of Xinjiang poplar may be associated with its morphological characteristics, including narrow crown, small planted spacing (2.0 $\mathrm{m} \times 5.0 \mathrm{~m})$ and high intensity of natural pruning. Furthermore, we found that $90 \%$ of sap flow of Xinjiang poplar occurred at 0.40 to 0.47 radius, which is nearly equal to that of the beech (Lüttschwager and Remus, 2007).

\subsection{Radial profile of $J_{s}$ responds to meteorological factors}

Various meteorological factors, including solar net radiation and VPD, have a broad and complex effect on sap flow. The effect of these meteorological factors can be consolidated into $E T_{0}$. This allows for the establishing of a simple relationship as opposed to calculating multiple linear regressions (Tognetti et al., 2004). Our correlation analysis showed that $E T_{0}$ has similar relationships with $J_{s}$, both in the outer and inner xylem, during the growing season, which was consistent with previous studies (Kubota et al., 2005; Oguntunde and Oguntuase, 2007). Some studies reported that the radial pattern of $J_{s}$ might change with soil water availability at different layers of soil, the radial pattern of $J_{s}$ may be a downward line when soil water is available for plant transpiration, whereas be upward toward the center of the trunk when trees are under water-stressed conditions (Fernández et al., 2001; Ford et al., 2004b; Nadezhdina et al., 2007b), which was not supported by our results. For ring-porous trees, such as Quercus pubescens, sap flow intensifies as it gets closer to the cambium due to increasing evaporative demand, which is related to hydraulic connections among leaves, xylem and sun-exposed foliage (Nadezhdina et al., 2002; Poyatos et al., 2007). However, for the diffuse-porous Xinjiang poplar, $J_{\mathrm{s}}$ of the various depth of the xylem, except for $J_{\mathrm{s} 1}$, displayed close relationships with $E T_{0}$ during the studied period. This study showed the strong correlation between sap flow and stomata activity from the canopy. We also concluded that it is preferable to validate sap flow with $E T_{0}$ whenever possible. The inner part of xylem of Xinjiang poplar supplied only a small amount of water to transpiring surfaces (Fig. 4), but still showed a strong relationship with $E T_{0}$ (Fig. 5). This agreed with previous report that an increase in water transport occurred in the inner sapwood due to high atmospheric evaporative demand (Ford et al., 2004b). However, the low sap flow at the outer xylem implied a slight decoupling with $E T_{0}$ (Fig. 5). This may be explained by previous reports that the sap flow in the outer xylem was dependent on water movement from the surface soil horizon (Čermák et al., 2008; Nadezhdina et al., 2008) because sandy soil moisture fluctuated frequently at our study site.

\subsection{Evaluation of instruments}

Thermal dissipation technique, which was proposed by Granier (1985), is the preferred method of measurement for $J_{s}$ because it is simple, continuously measurement, inexpensive, easy to install and not energy-demanding (Granier, 1985; Sevanto et al., 2008; Du et al., 2011). Nonlinear calibration between the index $(K)$ and $J_{s}$ in G-system had been validated for several woody species (Granier, 1985) and synthetic porous media (Granier's unpublished data). Its reliability had been verified by the studies that were performed in the field and on a sawdust column, the cut stem experiments in laboratories, and the pot or lysimeter experiments (Do and Rocheteau, 2002; McCulloh et al., 2007).

For large trees, variable lengths of needles in the G-system are necessary to ensure reliable measurement in both ring-porous and diffuse-porous species (James et al., 2002; Hultine et al., 2010). The original heat dissipation probes of $2 \mathrm{~cm}$ in length are substituted by probes of variable lengths, such as 
those of 2 to $12 \mathrm{~cm}$ (Krauss et al., 2007) and those of 20 to $30 \mathrm{~cm}$ ( $\mathrm{Lu}$ et al., 2000). Changing the probes does not invalidate the empirical relationships between $J_{s}$ and temperature difference as determined by Granier (McCulloh et al., 2007; Hultine et al., 2010). Reliance in both angiosperms and gymnosperms and the self-zeroing method of the Granier-type sensors makes the empirical relationship particularly impervious to changes in sensor design (Lu et al., 2000; James et al., 2002). In this study, we manufactured 8-cm-long probes, which are now commercially available from Dynamax Inc., US (McCulloh et al., 2007), in order to evaluate $J_{s}$ in the innermost xylem. However, the $8-\mathrm{cm}$ probes are still too short for measuring large trees. We believe that the improvements for accuracy (Delzon et al., 2004; Mahjoub et al., 2009; Ayutthaya et al., 2010) and some new alternative methods, such as heat field deformation (Nadezhdina et al., 2002), will help improve the precision and operability in the future.

The potential difference of $J_{s}$ in azimuthal and axial directions was initially considered and controlled for. The azimuthal variability of sap flow has been shown to correlate to crown architecture, but poorly relate to anatomical characteristics of the xylem (López-Bernal et al., 2010). Thus, for the dominant tree Xinjiang poplar, five probes were positioned within $40 \mathrm{~cm}$ in the axial direction and arranged in half circle in circumferential direction in order to minimize mutual interference between probes. This set-up is applicable for trees approximately $15 \mathrm{~m}$ tall.

\subsection{Correction coefficient for estimating sap flow}

The use of several sensors to account for radial variations of sap flow in trees during routine measurements is not practical. Therefore, identifying a correction coefficient is necessary for the estimation of sap flow across the sectional area of sapwood using a single-point measurement. Zang et al. (1996) reported the strong correlation between any two-point measurements along the xylem, which was verified in Xinjiang poplar in this study.

Steeper radial pattern of $J_{s}$ and tree-to-tree variation both highlighted the need for a simple approach for accurately estimating sap flow in one tree when $J_{s}$ is used to estimate canopy transpiration. The results of our regression analyses showed that the correction coefficient of 0.885 could be used to predict transpiration in Xinjiang poplar within the narrow range of tree sizes ( 30.04 to $31.20 \mathrm{~cm}$ of DBH). Our correction coefficient for Xinjiang poplar is nearly equal to the value (0.86) reported for Scots pine (3.82 to $4.86 \mathrm{~cm}$ of DBH) (Köstner et al., 1996). Basing on this value, we could multiply the sap flow obtained using the standard G-system by a correction coefficient, depending on sapwood thickness, to simplify the calculation process.

In this study, we collected the radial pattern of $J_{s}$ in Xinjiang poplar using multiple sensors at different depths of the xylem. We observed nearly consistent patterns of $J_{s}$ in a sample of three trees. We also calculated a reliable coefficient $\left(R^{2}=0.98\right)$ to be used to estimate sap flow by single-point measurement. We believed that a larger sample size could be beneficial for more complete understanding of radial function and for calculating a size-specific or age-specific coefficient.

\section{Conclusions}

Understanding the radial profile of $J_{s}$ and tree-to-tree variations is important for estimating transpiration based on sap flow. Our work presented a new case study for the radial pattern, the dynamics and the reliability of $J_{s .}$. We also investigated the possibility of estimating sap flow of a whole tree using a single 2-cm-deep probe in tall trees like Xinjiang poplar. We found that Xinjiang poplar has a steeper radial pattern of $J_{s}$ during the mid-growing season that fits the four-parameter GaussAmp equation. We found that approximately $50 \%$ of the total sap flow occurred within one-third of the outer radius, with the peak sap flow located at about 3 to $5 \mathrm{~cm}$ deep from the outer xylem, i.e. at 0.22 to 0.35 radius. In addition, the radial pattern of $J_{s}$ in Xinjiang poplar was not constant during within the same day, as well as between months. In particular, we found that the trees had steeper pattern in midday as compared to other time of the day. Diurnal fluctuations in the radial profiles of $J_{s}$ in June, July and August (the mid-growing season) were steeper than those in the other months of the year. The maximum difference of $J_{s}$ between the various depths of the xylem was observed in August, a month that also displayed the highest $E T_{0}$. In most cases, time-dependent changes of radial profile of $J_{s}$ (except 
at $1-\mathrm{cm}$ depth) were closely related to the daily changes of $E T_{0}$. We also found that the mean daily sap flow at the whole-tree level might be skewed by an under-estimation of $0.56 \%$ to an over-estimation of $29.69 \%$ when only a single probe at $2-\mathrm{cm}$ depth was used. Furthermore, accuracy of estimation could be improved by incorporating a correction coefficient of 0.885 , which was calculated basing on a standard $2-\mathrm{cm}$ probe. This can drastically simplify the calculation process of sap flow. Our results allow us to better understand the hydraulic characteristics within the xylem and to obtain precise estimation of the transpiration rate for tall trees.

\section{Acknowledgements}

This work was financially supported by the National Natural Science Foundation of China (31070628). We would like to thank ZhengGang GUO, Feng WANG, Feng DING and YongHua LI for their resourceful discussions and suggestions. Field support for this research was provided by Gansu Minqin National Studies Station for Desert Steppe Ecosystem. We also want to thank two anonymous reviewers for their helpful suggestions on an earlier version of the manuscript. We also gratefully acknowledge the Beijing Rainroot Technology Co., Ltd. (www.rainroot.com.cn) for its assistance in manufacturing the probes used in this study.

\section{References}

Allen R G, Pereira L S, Raes D, et al. 1998. Crop Evapotranspiration: Guidelines for Computing Crop Water Requirements. FAO Irrigation and Drainage Paper 56. Rome: Food and Agriculture Organization of the United Nations.

Ayutthaya S I N, Do F, Pannengpetch K, et al. 2010. Transient thermal dissipation method of xylem sap flow measurement: multi-species calibration and field evaluation. Tree Physiology, 30(1): 139-148.

Becker P. 1996. Sap flow in Bornean heath and dipterocarp forest trees during wet and dry periods. Tree Physiology, 16(1-2): 295-299.

Caylor K K, Dragoni D. 2009. Decoupling structural and environmental determinants of sap velocity: Part I. Methodological development. Agricultural and Forest Meteorology, 149(3): 559-569.

Čermák J, Nadezhdina N. 1998. Sapwood as the scaling parameterdefining according to xylem water content or radial pattern of sap flow? Annales des Sciences Forestières, 55(5): 509-521.

Čermák J, Nadezhdina N, Meiresonne L, et al. 2008. Scots pine root distribution derived from radial sap flow patterns in stems of large leaning trees. Plant and Soil, 305(1-2): 61-75.

Chang Z F, Han F G, Zhong S N. 2011. Response of desert climate change to global warming in Minqin, China. Journal of Desert Research, 31(2): 505-510.
Chen D Y, Wang Y K, Liu S Y, et al. 2014. Response of relative sap flow to meteorological factors under different soil moisture conditions in rainfed jujube (Ziziphus jujuba Mill.) plantations in semiarid Northwest China. Agricultural Water Management, 136: 23-33.

Chen L, Zhang Z, Li Z, et al. 2011. Biophysical control of whole tree transpiration under an urban environment in Northern China. Journal of Hydrology, 402(3): 388-400.

Cohen Y, Cohen S, Cantuarias-Aviles T, et al. 2008. Variations in the radial gradient of sap velocity in trunks of forest and fruit trees. Plant and Soil, 305(1-2): 49-59.

Delzon S, Sartore M, Granier A, et al. 2004. Radial profiles of sap flow with increasing tree size in maritime pine. Tree Physiology, 24(11): 1285-1293.

Do F, Rocheteau A. 2002. Influence of natural temperature gradients on measurements of xylem sap flow with thermal dissipation probes. 2 . Advantages and calibration of a noncontinuous heating system. Tree Physiology, 22(9): 649-654.

Du S, Wang Y L, Kume T, et al. 2011. Sapflow characteristics and climatic responses in three forest species in the semiarid Loess Plateau region of China. Agricultural and Forest Meteorology, 151(1): 1-10.

Fernández J E, Palomo M J, Díaz-Espejo A, et al. 2001. Heat-pulse measurements of sap flow in olives for automating irrigation: tests, root flow and diagnostics of water stress. Agricultural Water Management, 51(2): 99-123.

Fernández J E, Green S R, Caspari H W, et al. 2008. The use of sap flow measurements for scheduling irrigation in olive, apple and Asian pear trees and in grapevines. Plant and Soil, 305(1-2): 91-104.

Fiora A, Cescatti A. 2006. Diurnal and seasonal variability in radial distribution of sap flux density: implications for estimating stand transpiration. Tree Physiology, 26(9): 1217-1225.

Ford C R, Goranson C E, Mitchell R J, et al. 2004a. Diurnal and seasonal variability in the radial distribution of sap flow: predicting total stem flow in Pinus taeda trees. Tree Physiology, 24(9): 951-960.

Ford C R, McGuire M A, Mitchell R J, et al. 2004b. Assessing variation in the radial profile of sap flux density in Pinus species and its effect on daily water use. Tree Physiology, 24(3): 241-249.

Gartner B L, Meinzer F C. 2005. Structure-function relationships in sapwood water transport and storage. In: Holbroock $\mathrm{N}$ M, Zwieniecki M A. Vascular Transport in Plants. Oxford: Elsevier, 307-318.

Gebauer T, Horna V, Leuschner C. 2008. Variability in radial sap flux density patterns and sapwood area among seven co-occurring temperate broad-leaved tree species. Tree Physiology, 28(12): $1821-1830$.

González-Altozano P, Pavel E, Oncins J, et al. 2008. Comparative assessment of five methods of determining sap flow in peach trees. Agricultural Water Management, 95(5): 503-515.

Gonzalez-Benecke C A, Martin T A, Cropper W P. 2011. Whole-tree water relations of co-occurring mature Pinus palustris and Pinus elliottii var. elliottii. Canadian Journal of Forest Research, 41(3): 
509-523.

Granier A. 1985. A new method of sap flow measurement in tree stems. Annales des Sciences Forestières, 42(2): 193-200.

Granier A. 1987. Evaluation of transpiration in a Douglas-fir stand by means of sap flow measurements. Tree Physiology, 3(4): 309-320.

Guo S, Xu X, Yang Z, et al. 2011. Relationships between sap flow patterns of Ammopiptanthus mongolicus and environmental factors in desert areas. Acta Botanica Boreali-Occidentalia Sinica, 31(5): 1003-1010.

Hatton T J, Moore S J, Reece P H. 1995. Estimating stand transpiration in a Eucalyptus populnea woodland with the heat pulse method: measurement errors and sampling strategies. Tree Physiology, 15(4): 219-227.

Herbst M, Rosier P T, Morecroft M D, et al. 2008. Comparative measurements of transpiration and canopy conductance in two mixed deciduous woodlands differing in structure and species composition. Tree Physiology, 28(6): 959-970.

Hernández-Santana V, David T S, Martínez-Fernández J. 2008. Environmental and plant-based controls of water use in a Mediterranean oak stand. Forest Ecology and Management, 255(11): 3707-3715.

Horna V, Schuldt B, Brix S, et al. 2011. Environment and tree size controlling stem sap flux in a perhumid tropical forest of Central Sulawesi, Indonesia. Annals of Forest Science, 68(5): 1027-1038.

Hultine K, Nagler P, Morino K, et al. 2010. Sap flux-scaled transpiration by tamarisk (Tamarix spp.) before, during and after episodic defoliation by the saltcedar leaf beetle (Diorhabda carinulata). Agricultural and Forest Meteorology, 150(11): 1467-1475.

Hunt M A, Beadle C L. 1998. Whole-tree transpiration and water-use partitioning between Eucalyptus nitens and Acacia dealbata weeds in a short-rotation plantation in northeastern Tasmania. Tree Physiology, 18(8-9): 557-563.

Iida S, Tanaka T. 2010. Effect of the span length of Granier-type thermal dissipation probes on sap flux density measurements. Annals of Forest Science, 67(4): 408-417.

James S A, Clearwater M J, Meinzer F C, et al. 2002. Heat dissipation sensors of variable length for the measurement of sap flow in trees with deep sapwood. Tree Physiology, 22(4): 277-283.

Jiménez M S, Nadezhdina N, Čermák J, et al. 2000. Radial variation in sap flow in five laurel forest tree species in Tenerife, Canary Islands. Tree Physiology, 20(17): 1149-1156.

Köstner B, Biron P, Siegwolf R, et al. 1996. Estimates of water vapor flux and canopy conductance of Scots pine at the tree level utilizing different xylem sap flow methods. Theoretical and Applied Climatology, 53(1-3): 105-113.

Krauss K W, Young P J, Chambers J L, et al. 2007. Sap flow characteristics of neotropical mangroves in flooded and drained soils. Tree Physiology, 27(5): 775-783.

Kravka M, Krejzar T, Čermák J. 1999. Water content in stem wood of large pine and spruce trees in natural forests in central Sweden. Agricultural and Forest Meteorology, 98-99: 555-562.

Kubota M, Tenhunen J, Zimmermann R, et al. 2005. Influences of environmental factors on the radial profile of sap flux density in Fagus crenata growing at different elevations in the Naeba
Mountains, Japan. Tree Physiology, 25(5): 545-556.

Kumagai T, Aoki S, Shimizu T, et al. 2007. Sap flow estimates of stand transpiration at two slope positions in a Japanese cedar forest watershed. Tree Physiology, 27(2): 161-168.

López-Bernal Á, Alcántara E, Testi L, et al. 2010. Spatial sap flow and xylem anatomical characteristics in olive trees under different irrigation regimes. Tree Physiology, 30(12): 1536-1544.

Lu P, Müller W J, Chacko E K. 2000. Spatial variations in xylem sap flux density in the trunk of orchard-grown, mature mango trees under changing soil water conditions. Tree Physiology, 20(10): 683-692.

Lu P, Urban L, Zhao P. 2004. Granier's thermal dissipation probe (TDP) method for measuring sap flow in trees: theory and practice. Acta Botanica Sinica, 46(6): 631-646.

Lüttschwager D, Remus R. 2007. Radial distribution of sap flux density in trunks of a mature beech stand. Annals of Forest Science, 64(4): 431-438.

Mahjoub I, Masmoudi M M, Lhomme J P, et al. 2009. Sap flow measurement by a single thermal dissipation probe: exploring the transient regime. Annals of Forest Science, 66(6): 608 $\mathrm{P}_{1}-608 \mathrm{P}_{7}$.

McCulloh K A, Winter K, Meinzer F C, et al. 2007. A comparison of daily water use estimates derived from constant-heat sap-flow probe values and gravimetric measurements in pot-grown saplings. Tree Physiology, 27(9): 1355-1360.

Meinzer F C, James S A, Goldstein G. 2004. Dynamics of transpiration, sap flow and use of stored water in tropical forest canopy trees. Tree Physiology, 24(8): 901-909.

Nadezhdina N, Čermák J, Ceulemans R. 2002. Radial patterns of sap flow in woody stems of dominant and understory species: scaling errors associated with positioning of sensors. Tree Physiology, 22(13): 907-918.

Nadezhdina N, Čermák J, Meiresonne L, et al. 2007a. Transpiration of Scots pine in Flanders growing on soil with irregular substratum. Forest Ecology and Management, 243(1): 1-9.

Nadezhdina N, Nadezhdin V, Ferreira M I, et al. 2007b. Variability with xylem depth in sap flow in trunks and branches of mature olive trees. Tree Physiology, 27(1): 105-113.

Nadezhdina N, Ferreira M I, Silva R, et al. 2008. Seasonal variation of water uptake of a Quercus suber tree in Central Portugal. Plant and Soil, 305(1-2): 105-119.

Nourtier M, Chanzy A, Granier A, et al. 2011. Sap flow measurements by thermal dissipation method using cyclic heating: a processing method accounting for the non-stationary regime. Annals of Forest Science, 68(7): 1255-1264.

Oguntunde P G, Oguntuase A M. 2007. Influence of environmental factors on the sap flux density of mango trees under rain-fed cropping systems in West Africa. International Journal of Plant Production, 1(2): 179-188.

Pereira A R, Green S, Nova V N A. 2006. Penman-Monteith reference evapotranspiration adapted to estimate irrigated tree transpiration. Agricultural Water Management, 83(1-2): 153-161.

Phillips N, Oren R, Zimmermann R. 1996. Radial patterns of xylem sap flow in non-, diffuse- and ring-porous tree species. Plant, Cell \& Environment, 19(8): 983-990.

Poyatos R, Čermák J, Llorens P. 2007. Variation in the radial patterns 
of sap flux density in pubescent oak (Quercus pubescens) and its implications for tree and stand transpiration measurements. Tree Physiology, 27(4): 537-548.

Saveyn A, Steppe K, Lemeur R. 2008. Spatial variability of xylem sap flow in mature beech (Fagus sylvatica) and its diurnal dynamics in relation to microclimate. Botany, 86(12): 1440-1448.

Sevanto S, Hölttä T, Nikinmaa E. 2008. The effects of heat storage during low flow rates on the output of Granier-type sap-flow sensors. Acta Horticulturae, 846: 45-52.

Solomon S D, Qin M, Manning Z, et al. 2007. Climate Change 2007: the Physical Science Basis. Contribution of Working Group I Contribution to the Fourth Assessment Report of the Intergovermental Panel on Climate Change. New York: Cambridge University Press, 1-996.

Steppe K, De Pauw D J W, Doody T M, et al. 2010. A comparison of sap flux density using thermal dissipation, heat pulse velocity and heat field deformation methods. Agricultural and Forest Meteorology, 150(7-8): 1046-1056.

Tateishi M, Kumagai T, Suyama Y, et al. 2010. Differences in transpiration characteristics of Japanese beech trees, Fagus crenata, in Japan. Tree Physiology, 30(6): 748-760.

Tognetti R, d'Andria R, Morelli G, et al. 2004. Irrigation effects on daily and seasonal variations of trunk sap flow and leaf water relations in olive trees. Plant and Soil, 263(1): 249-264.

Tyree M T, Zimmermann M H. 2002. Xylem Structure and the Ascent of Sap. Berlin: Springer-Verlag, 1-283.

Wullschleger S D, King A W. 2000. Radial variation in sap velocity as a function of stem diameter and sapwood thickness in yellow-poplar trees. Tree Physiology, 20(8): 511-518.

Wullschleger S D, Hanson P, Todd D. 2001. Transpiration from a multi-species deciduous forest as estimated by xylem sap flow techniques. Forest Ecology and Management, 143(1): 205-213.

Xu X Y, Tong L, Li F S, et al. 2011. Sap flow of irrigated Populus alba var. pyramidalis and its relationship with environmental factors and leaf area index in an arid region of Northwest China. Journal of Forest Research, 16(2): 144-152.

Zang D, Beadle C L, White D A. 1996. Variation of sapflow velocity in Eucalyptus globulus with position in sapwood and use of a correction coefficient. Tree Physiology, 16(8): 697-703. 